\title{
PENGEMBANGAN MODEL LOGIKA EVALUASI PROGRAM PENGEMBANGAN SDM RESPONSIF GENDER BIDANG ESDM
}

\author{
ROHMATULLOH ${ }^{1,2}$ DAN MOHAMMAD IMAM SHALAHUDDIN ${ }^{2}$ \\ ${ }^{1}$ Sekretariat Badan Diklat Energi dan Sumber Daya Mineral, Jakarta \\ Jl. Jend. Gatot Subroto Kav. 49, Jakarta 12950 \\ ${ }^{2}$ Jurusan Teknik Industri Politeknik Swadharma, Jakarta \\ Jl. Raya Pondok Cabe No. 36, Tangerang Selatan - Banten \\ Surel: rohmatulloh@diklat.esdm.go.id; imamshalahudin@gmail.com
}

\begin{abstract}
ABSTRAK
Model logika adalah alat untuk menceritakan program dalam rangka membantu pelaksanaan evaluasi. Secara sederhana, model logika terdiri dari keterkaitan elemen input-aktifitas-output-outcome. Tujuan kajian ini yaitu pengembangan model logika evaluasi program pengembangan sumber daya manusia (SDM) bidang energi dan sumber daya mineral (ESDM) terkait dengan isu pengarusutamaan gender. Pengembangan model menggunakan pendekatan kiri ke kanan atau logika maju. Hasilnya adalah sebuah model awal berdasarkan hasil penyusunan model yang dilakukan secara berulang-ulang untuk mendapat hasil yang mirip dengan kondisi nyata pengembangan SDM responsif gender. Outcome program yang diharapkan dengan meningkatnya partisipasi perempuan dalam mengikuti kegiatan pengembangan SDM seperti diklat/penyuluhan, bimbingan teknis, dan forum komunikasi adalah meningkatnya kompetensi dan kontribusi perempuan dalam pengelolaan sektor ESDM di unit kerjanya. Model ini dapat digunakan untuk evaluasi dan disempurnakan sesuai dengan kebutuhan dan masukan ide pemangku kepentingan.
\end{abstract}

Kata kunci: model logika, evaluasi program, pengembangan SDM, responsif gender

\begin{abstract}
Logic model is a tool for telling the program in order to facilitate the evaluation. In a simple way, this model consists of the interrelation among the input-activity-output-outcome elements. This research aims to analyse the development of logic model for evaluating the human resources develoment in energy and mineral resources sectors related to the gender mainstreaming issue. It is developed through left-toright approach or forward logic. The result of study is the initial model based on the model development iteratively to achieve such outcomes the closest to the real conditions in gender-responsive human resources development. Expected program outcomes with increasing women's participation in the following human resource development activities such as training, technical assistance, and the communication forum are increasing competence and role of women in the management of energy and mineral resources sector. This model can be used to evaluation process and enhanced in accordance with the needs and inputs from the stakeholders.
\end{abstract}

Key words: logic model, program evaluation, human resources development, gender responsive

\section{PENDAHULUAN}

Evaluasi program merupakan salah satu tahapan penting dalam siklus perencanaan. Evaluasi dalam kaitannya dengan sebuah program diklat adalah proses penerapan prosedur ilmiah untuk mengumpulkan informasi yang valid dan reliabel untuk membuat keputusan tentang program diklat (Purwanto dan Suparman, 1999). Keputusan tersebut nantinya akan berpengaruh terhadap keberlangsungan sebuah program apakah diteruskan atau dihentikan berdasarkan kinerjanya saat diimplementasikan. Untuk menghasilkan keputusan yang baik dan bermutu dari hasil proses evaluasi, maka sebuah 
program pada tahap perencanaan evaluasi harus didefinisikan dahulu dengan jelas struktur sistemnya. Struktur sistem program yang jelas yakni program yang dapat memberikan gambaran keterkaitan antar elemen (input-proses-outputoutcome) yang bekerja di dalamnya. Sehingga menjadi jelas ke mana tujuan yang hendak dicapai dan sumberdaya apa saja yang digunakan untuk menjalankan program tersebut. Struktur sistem program selanjutnya dimodelkan secara visual dan masuk akal, sehingga model yang dihasilkan memiliki kemiripan dengan kondisi nyata.

Model logika digunakan sebagai alat untuk memodelkan struktur program. Model logika adalah metode visual untuk menyampaikan sebuah ide yang menguraikan dan membagi pemahaman keterkaitan antar elemen untuk mengoperasikan sebuah program atau usaha perubahan (Knowlton and Phillips, 2012). McLaughlin and Jordan (1999) mendefinisikan model logika sebagai alat untuk menceritakan kinerja program dalam rangka menjawab pertanyaan-pertanyaan diantaranya: apa yang coba dicapai dan mengapa program tersebut dianggap penting, bagaimana mengukur efektifitasnya, dan bagaimana melakukannya dengan benar. Sedangkan menurut W.K. Kellog Foundation (2004), model logika adalah sebuah gambar bagaimana program bekerja dengan teori dan asumsi yang mendasarinya.

Model logika bukan merupakan sesuatu yang baru, karena menurut sejarahnya model ini telah digunakan sejak tahun 1970-an. Model logika adalah sebuah istilah umum dan dalam prakteknya nanti akan banyak ditemukan dengan istilah lain seperti peta ide (idea maps), kerangka kerja (framework), rich pictures, peta aksi, peta strategi (strategy maps), dan model mental (causal loop diagrams). Perbedaan penggunaan istilah tersebut biasanya disesuaikan dengan bidang penerapannya seperti dalam system dynamics lebih populer dengan istilah causal loop diagrams (Knowlton and Phillips, 2012). Model logika cukup populer khususnya bagi kalangan perencana dan peneliti yang bekerja dalam mendesain, mengimplementasikan, dan mengevaluasi program pembangunan dan proyek-proyek sosial yang didanai pemerintah, lembaga penyandang dana seperti W.K. Kellog Foundation dan The United Way, lembaga internasional seperti The U.S. Agency for International Development (USAID), serta perusahaan swasta. Perusahaan swasta menggunakannya untuk peningkatan kinerja dan mutu produk (W.K. Kellog Foundation, 2004; Taylor-Powell and Henert, 2008; Crane, 2010).

Penelitian terdahulu dalam pengembangan model logika telah banyak dilakukan di berbagai bidang dan hasilnya dapat membantu proses pelaksanaan evaluasi sebuah program secara efektif. Kang (2013) membuat model logika untuk analisis teknologi pada program penelitian dan pengembangan (litbang). West (2014), Hayes et al. (2011), dan Crane (2010) telah mengembangkan sebuah model logika di bidang pelayanan kesehatan dan program pengakuan profesi keperawatan (kredensial) dan pelatihan pengembangan keluarga. Pengembangan model oleh Crane (2010) menggunakan sumber daya pengetahuan dan pengalaman praktisnya dalam menjalani program tersebut di Cornell University. Taylor-Powell and Henert (2008) memberikan beberapa contoh model logika di bidang pendidikan, kesehatan, dan keuangan. McLaughlin and Jordan (1999) memberikan contoh sebuah model logika pada program litbang efisiensi pemanfaatan energi. Dalam bidang sumber daya manusia (SDM), $\mathrm{Oz}$ and Seren (2012) telah mengembangkan dua model logika tingkat strategis dan fungsional untuk pengembangan SDM menggunakan metode sistem penilaian kinerja karyawan 360 derajat. Pengembangan model logika di bidang pendidikan telah dikembangkan oleh Hendarti et al. (2014) untuk analisis pemilihan metode pembelajaran mata kuliah kewirausahaan.

Berdasarkan gambaran penelitian terdahulu di atas, kajian pengembangan model logika untuk evaluasi program pengembangan SDM bidang energi dan sumber daya mineral (ESDM) responsif gender relevan dalam rangka memecahkan permasalahan yang dihadapi pelaksana evaluasi 
pada program tersebut. Permasalahannya adalah tidak tersedianya gambaran program yang jelas untuk membantu proses pelaksanaan evaluasi. Ketidaktersediaan model yang berisi keterkaitan antar input, aktifitas, output, dan outcome yang jelas, maka dapat dipastikan hasil evaluasi tidak akan mampu menjawab keinginan pemangku kepentingan dan pengelola diklat terhadap capaian hasil kinerja selama ini. Akhirnya, pimpinan tidak dapat membuat keputusan yang baik apakah program ini sebaiknya dihentikan atau dilanjutkan pada periode berikutnya dengan beberapa perbaikan strategi. Untuk menjawab permasalahan tersebut, maka tujuan kajian ini adalah mengidentifikasi struktur sistem program dan mengembangkan model logika evaluasi program pengembangan SDM responsif gender bidang ESDM.

\section{METODE}

Kajian ini dibagi menjadi dua bagian yaitu penentuan program dan pengembangan model logika. Pengembangan model menggunakan pendekatan kiri ke kanan (left-to-right approach). Pendekatan ini dipilih karena program pengembangan SDM responsif gender bidang ESDM telah diimplementasikan namun belum memiliki model logika. Pendekatan ini dimulai dengan merumuskan input dan aktifitas atau kegiatan program. Selanjutnya bergerak ke kanan dengan mengajukan pertanyaan "mengapa". Pendekatan ini seperti rangkaian hubungan "If ...., Then ...." (Sundra et al., 2003). Sumber data adalah data primer dan sekunder. Data primer diperoleh melalui diskusi dengan ahli bidang gender pada kegiatan workshop dan sosialisasi yang difasilitasi Kementerian Pemberdayaan Perempuan dan Perlindungan Anak. Data sekunder diperoleh dari kajian pustaka dan laporan-laporan periode tahun 2011-2013. Analisis data menggunakan analisis deskriptif.

\section{Penentuan Program}

Bagian penentuan program terdiri dari tiga tahap, yaitu identifikasi masalah yang terkait dengan proses pelaksanaan evaluasi program pengembangan SDM bidang ESDM, perumusan masalah dan tujuan kajian, dan penentuan program. Tahapan identifikasi masalah dalam proses pelaksanaan evaluasi yang sering ditemukan berdasarkan pengalaman penulis dan penanggung jawab program adalah belum adanya deskripsi struktur sistem dan model program yang jelas. Berdasarkan pada permasalahan tersebut, selanjutnya dirumuskan masalah dan tujuan kajian pada tahap kedua.

Tahap ketiga adalah penentuan program pengembangan SDM bidang ESDM yang akan didesain modelnya. Penulis memilih program pengembangan SDM bidang ESDM dengan alasan bahwa program responsif gender termasuk isu strategis pemerintah yang harus dilaksanakan oleh setiap Kementerian/Lembaga serta Pemerintah Daerah. Berdasarkan kajian pemeringkatan prioritas isu strategis dengan metode Technique for order of preference by similarity to ideal solution (TOPSIS), isu Pengarusutamaan Gender (PUG) termasuk ke dalam prioritas kelima dari lima isu strategis Badan Diklat ESDM pada tahun 2012 (Rohmatulloh dan Winarni, 2014).

\section{Pengembangan Model}

Bagian pengembangan model adalah inti dari kajian ini. Bagian ini merupakan proses pemodelan yang terdiri dari analisis situasi kontekstual program, identifikasi elemen utama, penyusunan peta model logika program, dan verifikasi model. Tahap analisis situasi kontekstual program menggambarkan sekilas isu strategis PUG yang mendasari penerapan program pengembangan SDM bidang ESDM. Selanjutnya identifikasi elemen utama untuk membangun model logika program yaitu elemen sumber daya untuk menjalankan program sampai dengan outcome yang dikehendaki.

Hasil tersebut selanjutnya menjadi bahan untuk menyusun peta model logika menggunakan bentuk yang umum. Kegiatan dalam proses ini dilakukan secara berulang-uang (iteratif) untuk mendapatkan model logika evaluasi program yang mirip dengan realitas. Sebagaimana yang 
diuraikan Eriyatno (1998) bahwa pemodelan merupakan proses iteratif, dimana hasil pada setiap langkah dikembalikan lagi untuk diperbaiki agar didapatkan hasil yang mendekati model aslinya (dunia nyata) yang cukup ideal untuk dapat dijadikan representasi.

Verifikasi dilakukan selama proses penyusunan model logika menggunakan rangkaian pertanyaan if-then. Jika terdapat hubungan yang tidak logis dalam rangkaian if-then tersebut maka langsung diperiksa dan diperbaiki dengan yang lebih sesuai. Setelah model selesai dibuat selanjutnya verifikasi akhir oleh penanggung jawab dan pelaksana program melalui diskusi terbatas. Panduan untuk melakukan verifikasi akhir model menggunakan acuan pertanyaan yang dikembangkan oleh McLaughlin and Jordan (1999). Keempat pertanyaan tersebut adalah: (a) apakah tingkatan dalam model telah cukup dalam memberikan pemahaman tentang elemen-elemen dan keterkaitannya, (b) apakah model logika telah lengkap, (c) apakah semua elemen telah logis dan apakah masih ada jalur lain yang logis untuk mencapai hasil program, dan (d) apakah seluruh faktor luar telah diidentifikasi dan potensi yang memengaruhi telah diuraikan.

\section{HASIL DAN PEMBAHASAN}

Model logika evaluasi program pengembangan SDM responsif gender bidang ESDM yang telah dihasilkan dari seluruh tahapan pemodelan dan dilakukan secara berulang-ulang sebanyak delapan iterasi disajikan pada Gambar 1. Peta ini menggunakan bentuk umum model logika terdiri dari keterkaitan elemen input-aktifitasoutput-outcome. Input dapat terdiri dari sumber daya manusia, keuangan, kemitraan, kebutuhan pelanggan, dan sumber daya lainnya yang dapat mendukung berjalannya sebuah program. Aktifitas atau proses meliputi seluruh tahapan aksi yang diperlukan untuk menghasilkan output. Output adalah produk berupa barang atau jasa yang disediakan langsung untuk pelanggan. Outcome dicirikan sebagai perubahan atau manfaat yang dihasilkan dalam periode tertentu (jangka pendek, menengah, dan panjang) dari adanya aktifitas dan output yang dihasilkan (McLaughlin and Jordan, 1999). Outcome program pada model ini hanya menggunakan satu jangka waktu yaitu jangka pendek (1-2 tahun).

\section{Situasi Kontekstual Program}

PUG merupakan kewajiban yang harus dilaksanakan oleh seluruh instansi pemerintah pusat dan daerah. Pelaksanaan kewajiban ini sesuai dengan Instruksi Presiden Nomor 9 Tahun 2000 tentang Pengarusutamaan Gender dalam Pembangunan Nasional. Isu PUG merupakan suatu strategi untuk mencapai kesetaraan dan keadilan gender melalui kebijakan dan program yang memperhatikan pengalaman, aspirasi, kebutuhan, dan permasalahan perempuan dan laki-laki ke dalam proses perencanaan, pelaksanaan, pemantauan, dan evaluasi atas seluruh kebijakan dan program di berbagai bidang kehidupan dan sektor pembangunan (Supendi, 2011). Seperti diketahui bersama bahwa gender merupakan isu dalam pembangunan di berbagai sektor. Isu gender menjadi penting karena pembangunan harus melibatkan semua pihak dan hasilnya mesti memberikan manfaat pada berbagai segmen masyarakat baik segmen laki-laki maupun perempuan sesuai dengan kebutuhan, manfaat, tanggung jawab, dan perannya. Hal ini perlu mendapat penekanan agar kenyataan yang selama ini terjadi bahwa pengelolaan dan hasil pembangunan di berbagai sektor lebih banyak dilakukan dan dirasakan manfaatnya secara eksklusif oleh segmen atau kelompok masyarakat tertentu saja dapat dihindari.

Sektor ESDM juga tidak luput dari kenyataan yang memberi penilaian bahwa sektor ini tidak sensitif terhadap isu gender. Banyak yang beranggapan bahwa sektor ESDM yang mengelola sub sektor minyak dan gas bumi, mineral dan batu bara, ketenagalistrikan, energi baru terbarukan dan konservasi energi, dan kegeologian hanya dapat dilakukan oleh segmen laki-laki, sehingga manfaatnya juga tidak tersebar secara adil kepada semua segmen. Alasan bagi yang memandang 


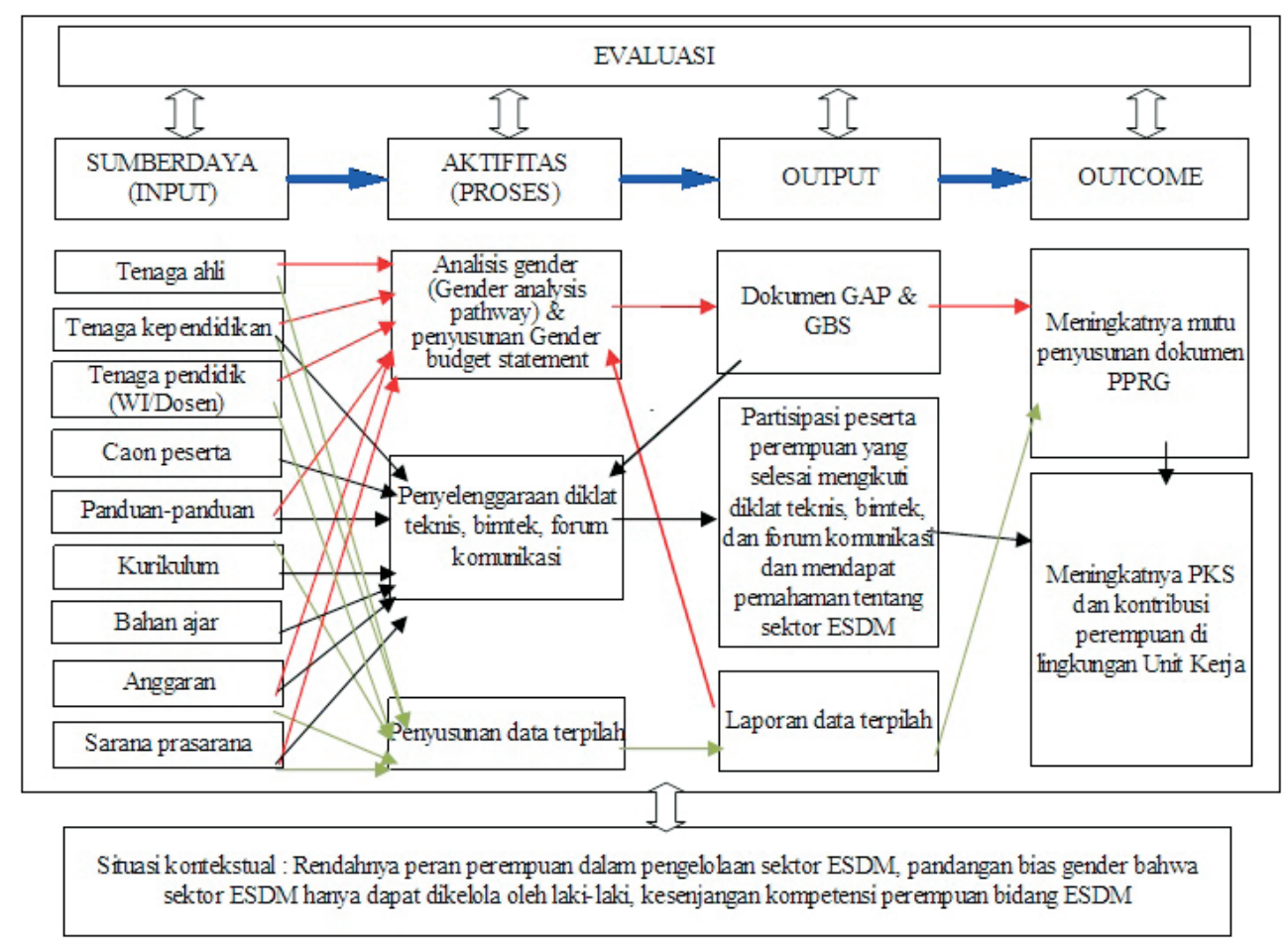

Gambar 1. Model Logika Evaluasi Program Pengembangan SDM Responsif Gender

bahwa sektor ini tidak sensitif gender adalah karena sifat pekerjaannya banyak dilakukan di lapangan dengan kesulitan tinggi sehingga hanya cocok dilakukan oleh segmen laki-laki yang memiliki kekuatan fisik dan tingkat kemampuan yang tinggi. Pandangan tidak sensitif gender ini, langsung maupun tidak langsung akhirnya memberi kesan bahwa pengelolaan sektor ESDM seluruhnya tidak membutuhkan peran perempuan.

Badan Diklat ESDM telah mengakomodasi isu PUG dalam program pengembangan SDM bidang ESDM seperti kegiatan diklat (penyuluhan, bimbingan teknis, dan forum komunikasi). Pengintegrasian PUG dalam kegiatan pengembangan SDM sebagian besar tidak dibuat secara baru dan terpisah antara lakilaki dan perempuan, melainkan hanya mengoreksi terhadap kegiatan yang telah dilaksanakan setiap tahun (existing) untuk dimasukkan isu keadilan gender. Pengintegrasian ini dengan memperhatikan aspek pengalaman, kebutuhan, dan permasalahan laki-laki dan perempuan dalam rangka peningkatan peran dan partisipasi

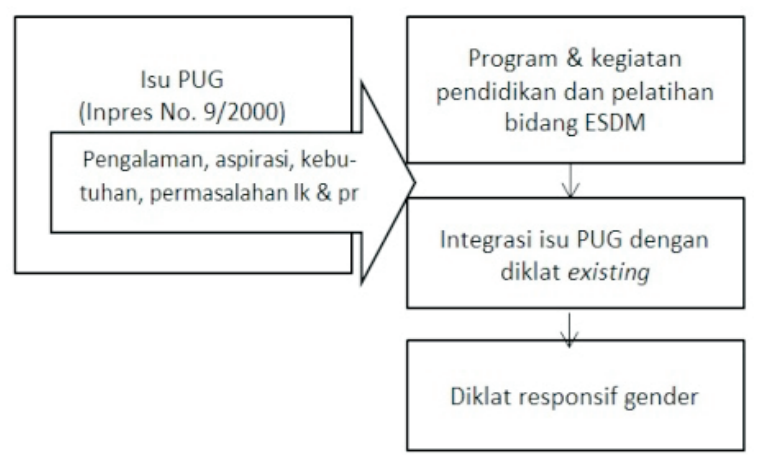

Gambar 2. Pengintegrasiaan Isu PUG pada Diklat Bidang ESDM

perempuan dalam kegiatan diklat responsif gender seperti ditunjukkan pada Gambar 2.

\section{Sumberdaya}

Dalam rangka merespon isu PUG untuk menjalankan program pengembangan SDM responsif gender bidang ESDM diperlukan sumber daya terdiri dari:

a. Tenaga ahli gender yang terlibat dalam proses pendampingan untuk melakukan analisis 
gender, mengoreksi kegiatan diklat yang ada untuk diintegrasikan isu gender, dan penyusunan data terpilah. Program responsif gender merupakan kegiatan baru sehingga memerlukan keterlibatan tim ahli secara intensif sampai program ini benar-benar mapan dijalankan Badan Diklat ESDM. Tim ahli mentrasfer pengetahuan kepada SDM kependidikan Badan Diklat ESDM melalui kegiatan workshop maupun seminar.

b. SDM kependidikan yang ikut terlibat dalam program yaitu penanggung jawab masingmasing satuan kerja di lingkungan Badan Diklat ESDM.

c. SDM pendidik yaitu Widyaiswara (WI) dan Dosen yang ikut terlibat khususnya dalam pelaksanaan kegiatan diklat, penyuluhan, bimbingan teknis, dan forum komunikasi. Peran tenaga pendidik sangat penting dalam setiap pelaksanaan aktifitas-aktifitas pengembangan SDM responsif gender.

d. Calon peserta perempuan yang ditargetkan ikut diklat, penyuluhan, bimbingan teknis, dan forum komunikasi berasal dari aparatur Kementerian ESDM, aparatur pemerintah daerah, dan masyarakat. Rekruitmen calon peserta menggunakan jejaring kerja sama yang sudah terjalin dengan baik selama ini. Selanjutnya calon peserta diseleksi oleh tim seleksi peserta diklat dengan memeriksa persyaratan yang telah ditetapkan tim.

e. Panduan-panduan merupakan sumber daya penting untuk menjalankan program tersebut. Penyusunan analisis gender dan data terpilah merupakan kegiatan yang baru pertama kali dilakukan oleh penanggung jawab kegiatan. Oleh karena itu dengan adanya buku panduan dapat membantu dalam pelaksanaan penyusunan dokumen gender dengan baik dan benar. Aktifitas penyelenggaraan diklat responsif gender juga memerlukan panduan untuk membimbing peserta dan penyelenggara diklat dalam mendukung keberhasilan pelaksanaan diklat.

f. Perangkat kurikulum yang memuat rencana pengembangan pengetahuan, pemahaman, kemampuan, nilai, sikap, dan minat peserta diklat agar dapat melakukan sesuatu dalam bentuk kemahiran, ketepatan, dan keberhasilan dengan penuh tanggung jawab.

g. Bahan ajar dan modul yang disusun oleh WI merupakan panduan bagi peserta diklat agar tercipta kondisi yang memungkinkan peserta untuk belajar dengan baik.

h. Anggaran untuk menjalankan program ini tersedia dan tidak mendapat hambatan dalam proses pengalokasiannya.

i. Sarana dan prasarana untuk menjalankan program khusus untuk kegiatan diklat (teori dan praktek) tersedia secara lengkap pada masing-masing satuan kerja di lingkungan Badan Diklat ESDM.

\section{Aktifitas atau Kegiatan}

Penyusunan aktifitas mengacu pada kemampuan dan ketersediaan sumber daya yang dimiliki saat ini. Aktifitas yang dilaksanakan untuk mendukung program pengembangan SDM responsif gender adalah sebagai berikut:

a. Analisis Gender

Analisis gender adalah proses menganalisis data dan informasi secara tematik tentang status, pola hidup laki-laki dan perempuan dalam program pembangunan dan faktor yang memengaruhinya (ekonomi, sosial, budaya, politik, hukum perundang-undangan). Model yang digunakan untuk analisis gender adalah model Gender Analysis Pathway (GAP). Tujuan analisis gender yaitu untuk mengetahui latar belakang terjadinya kesenjangan gender, mengidentifikasi aspek kesenjangan gender (akses, peran, kontrol dan manfaat yang diperoleh), merumuskan permasalahan sebagai akibat adanya kesenjangan gender, dan mengidentifikasi langkah-langkah atau tindakan intervensi yang diperlukan (Anon, 2010).

Analisis gender menggunakan model GAP telah dilakukan Badan Diklat ESDM pada tahun 2010 dengan pendampingan tim tenaga ahli gender dari Kementerian Pemberdayaan Perempuan dan Perlindungan Anak. Hasil identifikasi kegiatan pengembangan SDM bidang ESDM yang menjadi bahan pertimbangan untuk mengakomodasi kebutuhan dan peran perempuan adalah 
penyuluhan pengelolaan sampah untuk energi listrik (biomasa). Analisis gender selanjutnya dilakukan pada tahun 2011 yaitu kegiatan pelatihan tenaga penyuluh lapangan penggunaaan LPG $3 \mathrm{Kg}$. Pemilihan judul pelatihan ini berdasarkan pertimbangan bahwa tingkat partisipasi perempuan dalam mengikuti pelatihan ini pada tahun 2010 masih sangat rendah yaitu sekitar $10 \%$. Padahal kegiatan penyuluhan ini bagi perempuan sangat penting karena perempuan lebih mudah melakukan pendekatan secara psikologis dalam menyampaikan pesan penggunaan LPG $3 \mathrm{Kg}$ dengan benar kepada pengguna yang sebagian adalah ibu-ibu rumah tangga. Perkembangan selanjutnya pada tahun 2012 Badan Diklat ESDM telah melakukan analisis gender untuk mengoreksi kegiatan diklat yang sudah dilaksanakan agar dapat mengakomodasi isu gender, khususnya pada diklat yang banyak memberikan ruang bagi perempuan sesuai dengan kebutuhan dan perannya.

b. Penyelenggaraan Diklat/Penyuluhan, Bimtek, dan Forum Komunikasi Responsif Gender Penyelenggaraan kegiatan pengembangan SDM yang mengakomodasi isu gender yaitu sebanyak tujuh judul kegiatan sesuai dengan jumlah dokumen gender budget statement (GBS) yang disusun dari hasil analisis gender. Judul kegiatan tersebut berupa diklat bidang ESDM, penyuluhan, bimbingan teknis, dan forum komunikasi dalam rangka peningkatan jumlah mahasiswa perempuan Program Studi Keinspekturan (Tabel 1).

c. Penyusunan Data Terpilah

Data Terpilah adalah data yang dipilah menurut jenis kelamin dan status, peran dan kondisi perempuan dan laki-laki di seluruh bidang pembangunan yang meliputi bidang kesehatan, pendidikan, ekonomi dan ketenagakerjaan, politik dan pengambilan keputusan, hukum dan sosial budaya dan kekerasan (Peraturan Menteri Pemberdayaan Perempuan dan Perlindungan Anak No. 06 Tahun 2009 tentang Penyelenggaraan Data Gender dan Anak). Manfaat data terpilah yaitu agar setiap unit dapat menyusun data terpilah secara baku, sehingga dapat digabungkan, untuk menjaga konsistensi metodologi penyusunan, untuk menjaga tingkat komparasi data dari tahun ke tahun, dan dokumentasi untuk dasar perbaikan (Surbakti, 2012). Penyusunan data terpilah tahap awal yaitu pemilahan data pegawai Badan Diklat ESDM.

\section{Output Aktifitas}

Output langsung berupa produk laporan dan peserta dari masing-masing aktifitas yang dilaksanakan untuk mendukung program pengembangan SDM responsif gender yaitu sebagai berikut:

a. Dokumen GAP dan Gender Budget Statement (GBS). Dokumen GAP dijadikan dasar untuk penyusunan GBS. Sedangkan dokumen GBS menjadi lampiran dokumen kerangka acuan kegiatan yang diintegrasikan isu gender. Dokumen GBS sebagai bentuk pernyataan bahwa instansi tersebut bersedia mengalokasikan kegiatan yang responsif gender. Output ini setiap tahun dihasilkan minimal satu dokumen khususnya untuk kegiatan diklat bidang ESDM, bimbingan teknis, dan forum komunikasi untuk

Tabel 1. Kegiatan Pengembangan SDM Responsif Gender Bidang ESDM

\begin{tabular}{ll}
\hline No. & \multicolumn{1}{c}{ Kegiatan } \\
\hline 1 & Bimtek Pengelola Pengadaan Barang dan Jasa \\
2 & Pelatihan Pengenalan Pertambangan Bagi Aparatur Non Teknis Daerah \\
3 & Pelatihan Penggunaan Global Positioning System dalam Menunjang Pengukuran Batas \\
& Wilayah Pertambangan \\
4 & Pelatihan Tenaga Penyuluh Lapangan Penggunaan LPG 3kg \\
5 & Pelatihan Pelaksanan Penyuluh Lapangan Mitigasi Bencana Gunung api \\
6 & Pelatihan Tenaga Penyuluh Pemanfaatan Energi Biogas \\
7 & Forum Komunikasi Untuk Peningkatan Jumlah Mahasiswi Prodi Keinspekturan \\
\hline
\end{tabular}


peningkatan jumlah mahasiswa perempuan Program Studi Keinspekturan.

b. Jumlah peserta perempuan yang selesai mengikuti diklat, bimbingan teknis, dan forum komunikasi dan mendapat pemahaman sektor ESDM. Jumlah peserta perempuan yang mengikuti kegiatan forum komunikasi diharapkan dapat meningkatkan minat calon mahasiswa perempuan untuk mengikuti pendidikan formal diploma Program Studi Keinspekturan.

c. Laporan data terpilah SDM Badan Diklat ESDM berisi data yang sudah dipilah ke dalam jenis kelamin laki-laki dan perempuan berdasarkan pendidikan, umur, pangkat dan golongan, dan jabatan. Hasil pemilahan ini menjadi data pembuka wawasan dalam penyusunan analisis gender untuk melihat ketimpangan yang ada seperti rendahnya tingkat partisipasi perempuan dalam mengikuti diklat.

\section{Outcome Program}

Berdasarkan identifikasi output langsung setiap aktifitas yang diuraikan di atas, selanjutnya dirumuskan outcome atau hasil dari berfungsinya sebuah output. Outcome program yang diharapkan terdiri dari dua capaian yaitu: meningkatnya mutu penyusunan dokumen perencanaan dan penganggaran responsif gender (PPRG) dan meningkatnya kompetensi (pengetahuan, keterampilan, dan sikap) dan peran perempuan dalam pengelolaan sektor ESDM di unit kerjanya. Outcome meningkatnya mutu penyusunan dokumen PPRG diharapkan dapat mendukung outcome utama program yaitu meningkatnya kompetensi dan kontribusi perempuan dalam pengelolaan sektor ESDM. Outcome utama program dapat terwujud dalam jangka waktu minimal satu tahun setelah selesainya mengikuti kegiatan pengembangan SDM.

\section{Verifikasi Model}

Berikut ini adalah proses verifikasi model pada salah satu aktifitas program analisis gender. Situasi kontekstual yang berkembang yaitu peran perempuan dalam pengelolaan sektor ESDM rendah, adanya pandangan bias gender, dan kesenjangan kompetensi perempuan bidang ESDM. If sumber daya tenaga ahli, tenaga pendidik dan kependidikan, saran dan prasarana, angggaran yang dimiliki untuk menjalankan aktifitas program, then aktifitas program analisis gender dan penyusunan GBS dapat dilaksanakan. If aktifitas tersebut selesai dilaksanakan, then menghasilkan output langsung berupa dokumen GAP dan GBS yang telah diselesaikan. If dokumen GAP dan GBS tersedia, then manfaat yang diraih dari berfungsinya output tersebut yaitu meningkatkan penyusunan dokumen Perencanaan dan Penganggaran Responsif Gender (PPRG). Terkait dengan aktifitas program penyelenggaraan diklat, If dokumen GAP dan GBS tersedia, then kegiatan diklat terkoreksi menjadi responsif gender. If aktifitas penyelenggrann diklat dilaksanakan, then menghasilkan produk langsung berupa partisipasi perempuan yang selesai mengikuti diklat dan mendapat pemahaman pengelolaan sektor ESDM. If perempuan telah mendapat pemahaman yang baik, then manfaat yang dicapai berupa peningkatan kompetensi (pengetahuan, keterampilan, dan sikap) serta berkontribusi di unit kerjanya.

Berdasarkan rangkaian pertanyaan di atas diperoleh jawaban sementara yang logis antar setiap elemen struktur program. Dengan demikian model telah disusun berdasarkan alasan yang logis. Selanjutnya verifikasi akhir model dengan pemangku kepentingan menggunakan panduan empat pertanyaan McLaughlin and Jordan (1999). Hasil verifikasi yaitu bahwa model telah memberikan pemahaman antar elemen dan keterkaitannya, model telah lengkap, elemen telah logis, dan faktor luar yang memengaruhi program telah diidentifikasi dengan jelas.

\section{SIMPULAN}

Hasil pemodelan program pengembangan SDM responsif gender diperoleh gambaran bahwa program tersebut didasari oleh isu kesenjangan gender dan rendahnya kompetensi perempuan 
dalam pengelolaan sektor ESDM. Dalam rangka memperkecil kesenjangan tersebut telah dialokasikan sumber daya yang cukup untuk menjalankan aktifitas. Output yang dihasilkan diharapkan langsung berfungsi terhadap capaian outcome program yaitu peningkatan kompetensi dan kontribusi perempuan dalam pengelolaan sektor ESDM di unit kerjanya. Model ini dapat dijadikan pegangan bagi penanggung jawab dan pelaksana program untuk melakukan evaluasi yang sistematis seperti menentukan indikator yang digunakan, menyusun pertanyaan evaluasi, metode pengumpulan dan analisis data, dan pada tingkat mana evaluasi akan difokuskan. Sedangkan bagi pemangku kepentingan, model ini dapat digunakan untuk mengetahui sejauh mana keberhasilan capaian kinerja outcome program yang diharapkan. Model ini dapat diperbaharui dan dikembangkan sesuai kebutuhan berdasarkan masukan ide yang berkembang dari para pemangku kepentingan.

\section{UCAPAN TERIMA KASIH}

Penulis mengucapkan terima kasih kepada Pimpinan dan Manajemen Sekretariat Badan Diklat ESDM yang telah memberikan kesempatan untuk mengikuti penyertaan diklat dan workshop peningkatan kompetensi dan Reviewer atas masukannya untuk perbaikan naskah ini.

\section{DAFTAR PUSTAKA}

Anon, 2010. Analisis Gender, Makalah Sosialisasi Pengarusutamaan Gender, Jakarta.

Crane, B., 2010. Using Qualitative Data to Refine a Logic Model for the Cornell Family Development Credential Program, The Qualitative Report, 15(4), 899-931.

Eriyatno, 1998. Ilmu Sistem : Meningkatkan Mutu dan Efektifitas Manajemen, Bogor: IPB Press.

Hayes, H., Parchman, M.L., and Howard, R., 2011. A Logic Model Framework for Evaluation and Planning in a Primary Care Practice-based Research Network (PBRN), The Journal of the American Board of Family Medicine, 24(5), 576582.

Hendarti, D.R., Setyanto, dan N.W., Rahman, A., 2014. Analisis Metode Pembelajaran Mata Kuliah Kewirausahaan dengan Metode Logic Model,
Jurnal Rekayasa dan Manajemen Industri, 2(2), 360-369.

Instruksi Presiden Republik Indonesia Nomor 9 Tahun 2000 tentang PUG dalam Pembangunan Nasional.

Kang, H-Y., 2013. Development of Logic Model for R\&D Program Plan Analysis in Preliminary Feasibility Study, International Journal of Social, Management, Economics and Business Engineering, 7(9), 1347-1350.

Knowlton, L.W., and Phillips, C.C., 2012. The Logic Model Guidebook: Better Strategies for Great Results, Second Edition, California: SAGE Publishing.

McLaughlin, J.A., and Jordan, G.B., 1999. Logic Models: A Tool for Telling Your Program's Performance Story, Evaluation and Program Planning, 2, 65-72.

Oz, O., and Seren, D.B., 2012. Developing the Application of 360 Degree Performance Appraisal through Logic Model, International Journal of Business and Social Science, 3(22), 280-286.

Peraturan Menteri Pemberdayaan Perempuan dan Perlindungan Anak Nomor 06 Tahun 2009 tentang Penyelenggaraan Data Gender dan Anak

Purwanto dan Suparman, A., 1999. Evaluasi Program Diklat, Jakarta: STIA LAN Press.

Rohmatulloh dan Winarni, S., 2014. TOPSIS Method for Determining The Priority of Strategic Training Program, International Journal on Advanced Science Engineering and Information Technology, 4(2), 31-34.

Sundra, D.L., Scherer, J., and Anderson, L.A., 2003. A Guide on Logic Model Development for CDC's Prevention Research Centre: Teaching and Training Guide, Atlanta: Prevention Research Centre.

Supiandi, Y., 2011. Pengarusutamaan Gender Bidang ESDM, Makalah Sosialisasi Implementasi $P P R G$, Bogor.

Surbakti, S., 2012. Penyusunan Data Terpilah. Makalah Workshop Penyusunan Data Terpilah, Mataram.

Taylor-Powell, E., and Henert, E., 2008. Developing a Logic Model: Teaching and Training Guide, University Of Wisconsin-Extension, Madison.

West, J., 2014. Public Health Program Planning Logic Model for Community Engaged Type 2 Diabetes Management and Prevention, Evaluation and Program Planning, 42, 43-49.

W.K. Kellog Foundation, 2004. Logic Model Development Guide : Using Logic Models to Bring Together Planning, Evaluation, and Action, Battle Creek, Michigan. 